\title{
DAMPAK LOYALITAS KONSUMEN DENGAN KUALITAS BARANG DAN STARTEGI HARGA PADA KEPUASAN KONSUMEN (STUDI PADA KONSUMEN ALFA MART DI WILAYAH SURAKARTA)
}

\author{
ARIS TRI HARYANTO \\ Sekolah Tinggi Ilmu Ekonomi AUB Surakarta \\ Email: Arishrayanto26@yahoo.co.id \\ SEPTIANA NOVITA DEWI \\ Sekolah Tinggi Ilmu Ekonomi AUB Surakarta \\ Email: novita.dewi@yahoo.co.id
}

\begin{abstract}
Abstrak
Penelitian ini bertujuan untuk mengetahui dampak loyalitas konsumen dengan kualitas barang dan startegi harga pada kepuasan konsumen (Studi pada Konsumen Alfa Mart di Wilayah Surakarta). Teknik analisis yang digunakan adalah path analysis (analisis jalur). Hasil penelitian ini : Kualitas barang berpengaruh signifikan terhadap kepuasan Konsumen. Strategi harga berpengaruh signifikan terhadap kepuasan Konsumen. Kualitas barang berpengaruh signifikan terhadap loyalitas Konsumen. Strategi harga berpengaruh tidak signifikan terhadap loyalitas Konsumen. Kualitas pelayanan berpengaruh signifikan terhadap loyalitas Konsumen. Kepuasan berpengaruh signifikan terhadap loyalitas Konsumen. Hasil uji $F$ dapat disimpulkan secara bersama-sama variabel kualitas barang, strategi harga dan kepuasan berpengaruh terhadap loyalitas Konsumen Alfamart di wilayah Surakarta. Hasil tersebut dapat dijelaskan bahwa $R 2$ total sebesar 0,918 dapat diartikan loyalitas konsumen Alfamart di wilayah Surakarta dijelaskan oleh variabel kualitas barang, strategi harga dan kepuasan sebesar 91,8\% dan sisanya 8,2\% dijelaskan variabel lain diluar model penelitian sebagai contoh : lokasi dan sarana prasarana. Hasil analisis jalur menunjukkan bahwa penggunaan intervening kepuasan untuk variabel kualitas barang dan strategi harga adalah tidak efektif, karena hasil pengaruh langsung lebih besar dibandingkan pengaruh tidak langsung.
\end{abstract}

Kata kunci: Kualitas Barang, Strategi Harga, Kepuasan Konsumen, Loyalitas Konsumen.

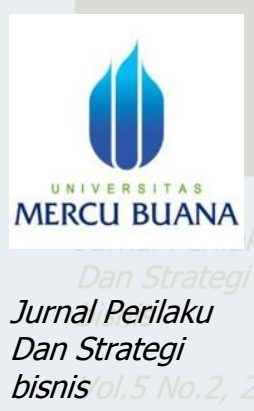

Vol.5 No.2, 2017

Hal. $161-167$

\section{PENDAHULUAN}

Perkembangan bisnis semakin maju dan berkompeten didalam persaingan di perekonomian di Indonesia dan di luar negeri. Pasar Tradisional semakin terpojok bila tidak diperbaiki manajemen yang ada kalah dengan pasar modern yang semakin bermunculan, hal ini terbukti banyaknya mini market yang berdiri di setiap kota kecamatan dan kelurahan 
maupun jalan raya yang ada, salah satu contoh Alfamart yang semakin banyak, sebagai embrio pasar modern. ini tidak dapat dipungkiri tidak luput dari persaingan yang semakin ketat dalam memasarkan barang dan jasa. Sehingga setiap perusahaan dituntut untuk selalu berusaha keras dalam berinovasi terhadap barang maupun jasanya agar mampu bertahan dari persaingan dan mampu menarik perhatian dari calon konsumen akan barang yang ditawarkan. Hal yang perlu diperhatikan sebelum merancang inovasi, seseorang harus jelas terlebih dahulu segmentasi dan target mana yang akan disasar.

Selain tiap perusahaan dituntut untuk lebih berinovasi, perusahaan juga diharapkan dapat memasarkan barang atau jasanya kepada calon konsumen, dengan tujuan agar barang tersebut dapat dikenal oleh masyarakat. (Kotler 2003). Tujuan pemasaran sendiri menurut seorang pakar teori manajemen terbuka Assauri (2009), adalah mengetahui dan memahami pelanggan dan selanjutnya mampu menjual dirinya sendiri. Idealnya, pemasaran harus memaksimalkan pelanggan yang siap membeli, yang dibutuhkan selanjutnya adalah menyediakan barang atau jasa itu. (Kotler 2003). Wilayah Surakarta banyak berkembang Alfamart yang menyediakan produk kebutuhan sehari-hari yang selalu dibutuhkan oleh konsumen setiap saat.

Menurut William (2003: 34) dalam buku dasar-dasar pemasaran, perencanaan strategi pemasaran berarti upaya menemukan peluang menarik dan penyusunan strategi pemasaran yang berlaba. Dimana stategi pemasaran menerapkan pasar target dan bauran pemasaran atau lebih dikenal dengan istilah 4P (product, place, promotion dan price) untuk barang dan ditambah 3P (people, process, physical evidence) untuk jasa. Product, process dan people merupakan tiga pilar service yang semuanya penting dan tidak dapat diabaikan oleh perusahaan. Penerapan strategi pemasaran yang tepat dapat mempengaruhi para calon konsumen untuk membuat suatu keputusan pembelian. Dimana keputusan konsumen dalam mengambil keputusan pembelian dipengaruhi oleh akal pemikiran atas informasi pengetahuan yang didapatkan.

Fornell, (2006:7) menyatakan loyalitas sebagai kemauan pelanggan untuk terus mendukung sebuah perusahaan dalam jangka panjang membeli dan menggunakan barang dan jasanya atas dasar rasa suka yang eklusif dan secara sukarela merekomendasikan barang perusahaan kepada orang lain. Untuk membentuk loyalitas konsumen perlu diperhatikan faktor-faktor yang dapat mempengaruhi, misalnya kualitas barang, strategi harga, kualitas pelayanan, citra dan kepuasan.

Strategi harga adalah jumlah dari seluruh nilai yang konsumen tukarkan untuk sejumlah manfaat dengan memiliki atau menggunakan suatu barang atau jasa. Kebanyakan strategi harga merupakan faktor utama yang mempengaruhi konsumen ketika membeli suatu barang, dengan harga yang murah konsumen akan lebih tertarikuntuk membeli sebuah produk di Alfamart yang memliki berbagai macam produk dan memliki harga yang bervariasi. Kualitas pelayanan merupakan suatu konsep tentang bagaimana menanamkan kualitas pelayanan pada setiap fase penyelenggaraan jasa dan melibatkan semua personil.

Dari pengamatan awal peneliti pada Alfamart di wilayah Surakarta peneliti menemukan fenomena bisnis yang terjadi semakin tajamnya persaingan dibidang minimarket dan mempertinggi loyalitas konsumen Alfamart karena ada persaingan yang terjadi antar 
perusahaan, maka perlunya peningkatan perbaikan pada Alfamart di wilayah Surakarta tentang kualitas barang atau produk yang selalu dijaga, harga selalu bersaing dengan perusahaan lain, kualitas pelayanan yang selalu diunggulkan dan kepuasan konsumen yang selalu diutamakan. Berangkat dari fenomena dan pemikiran-pemikiran di atas, maka untuk itulah kiranya penulis tertarik untuk melakukan penelitian mengenai "Pengaruh kualitas barang, strategi harga dan kualitas pelayanan terhadap loyalitas konsumen dengan citra dan kepuasan konsumen sebagai variabel intervening. (Studi pada konsumen Alfamart di wilayah Surakarta).

\section{PEMBAHASAN}

\section{Pengaruh Langsung dan Pengaruh Tidak Langsung dan Total Effect}

Diagram jalur berikut menunjukkan pengaruh langsung dan tidak langsung maupun pengaruh total penelitian ini.

Tabel 1.Hasil pengaruh langsung, tidak langsung dan total pengaruh

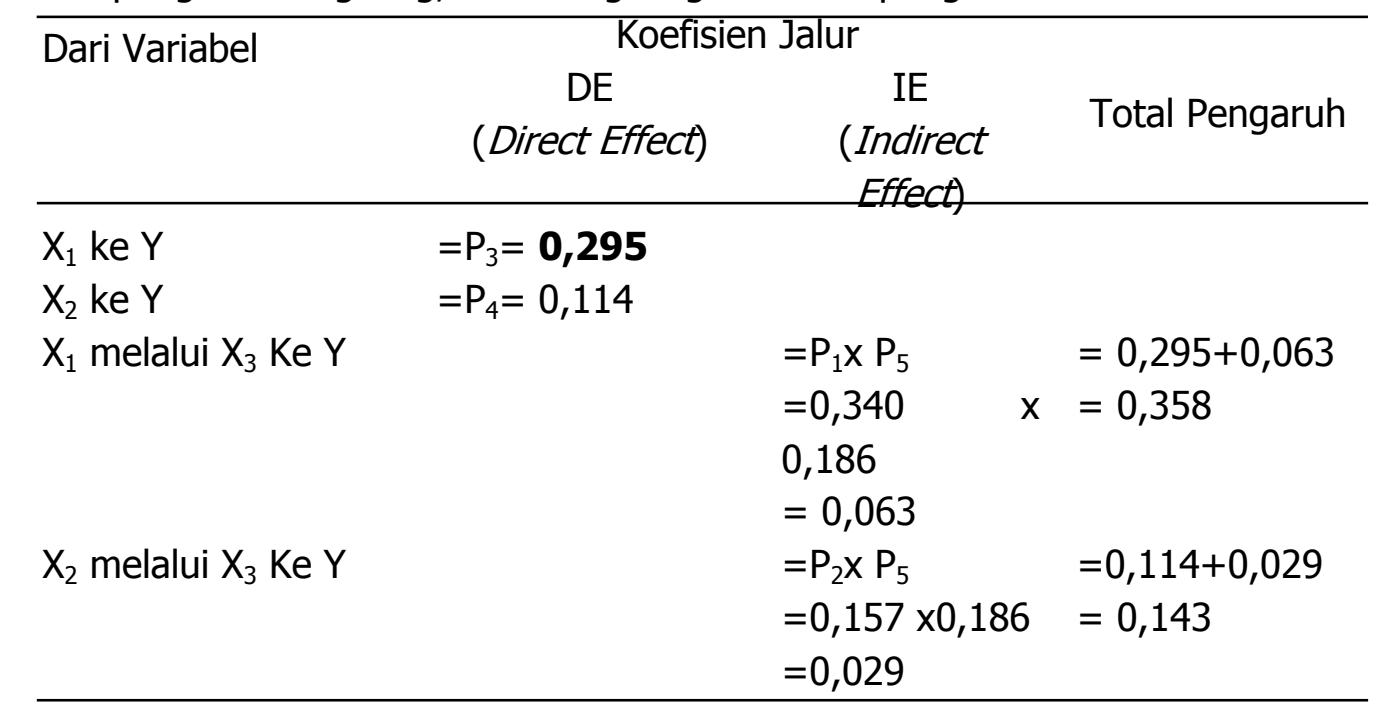

Sumber : Data yang diolah, 2016

\section{Pengaruh Strategi harga terhadap loyalitas melalui kepuasan.}

Hasil penelitian membuktikan bahwa dari analisis jalur ini menunjukkan bahwa penggunaan variabel intervening kepuasan dalam rangka peningkatan loyalitas, untuk variabel strategi harga adalah tidak efektif, karena pengaruh tidak langsung menghasilkan pengaruh yang lebih kecil, dari pada pengaruh langsung. Hal ini mengidentifikasikan bahwa dalam mempengaruhi loyalitas lebih perlu melakukan peningkatan strategi harga secara langsung.

Penelitian ini mendukung penelitian yang dilakukan oleh Mandela (2007), Liu Tsung dan Li (2007), Bontis dan Booker (2007) dan Adi Krismanto (2007), Setyo Budiarto (2011) bahwa terdapat pengaruh signifikan strategi harga terhadap loyalitas. Strategi harga yang tepat menjadi harapan para pelanggan dalam memenuhi kebutuhan berbelanja di Alfamart di wilayah Surakarta. Diperlukan usaha perusahaan dalam memenuhi dan mewujudkan harapan para konsumen tersebut. Hal ini yang dinyatakan oleh Kotler (2003) strategi harga dapat memberikan dorongan untuk dapat membuat konsumen menjadi loyal.

Contoh hal yang dapat meningkatkan strategi harga, langkah konkret yang dapat dilakukan adalah: 
1. Harga yang ditawarkan di Alfamart di wilayah Surakarta bervariasi.

2. Harga yang diberikan kepada konsumen sesuai dengan kualitas barang yang ditawarkan.

3. Harga di Alfamart di wilayah Surakarta tidak terlalu murah dan tidak terlalu mahal.

Dengan adanya keseragaman harga yang bervariasi, yang sesuai dengan harga pasar dan sesuai dengan kemampuan konsumen pada umumnya, maka konsumen akan merasa nyaman saat berbelanja sehingga akan menimbulkan sikap loyal terhadap Alfamart di wilayah Surakarta. Dengan hal tersebut, target penjualan Alfamart di wilayah Surakarta akan tercapai.

\section{Pengaruh kualitas barang terhadap loyalitas melalui Citra dan kepuasan.}

Hasil penelitian membuktikan bahwa dari analisis jalur ini menunjukkan bahwa penggunaan variabel intervening citra dan kepuasan dalam rangka peningkatan loyalitas, untuk variabel kualitas barang adalah tidak efektif, karena pengaruh tidak langsung menghasilkan pengaruh yang lebih kecil, dari pada pengaruh langsung. Hal ini berarti, untuk meningkatkan loyalitas Konsumen Alfamart di wilayah Surakarta sebaiknya meningkatkan kualitas barang secara langsung.

Penelitian ini mendukung penelitian yang dilakukan oleh Mandela (2007), Liu Tsung dan Li (2007), Bontis dan Booker (2007) dan Adi Krismanto (2007), Setyo Budiarto (2011) bahwa terdapat pengaruh signifikan kualitas barang terhadap loyalitas. Kualitas barang yang baik menjadi harapan para pelanggan dalam memenuhi kebutuhan berbelanja di Alfamart di wilayah Surakarta. Diperlukan usaha perusahaan dalam memenuhi dan mewujudkan harapan para konsumen tersebut. Hal ini yang dinyatakan oleh Kotler (2003) kualitas pelayanan dapat memberikan dorongan untuk dapat membuat konsumen menjadi loyal.

Contoh hal yang dapat dilakukan untuk meningkatkan kualitas barang yaitu dengan cara:

1. Kebersihan barang sudah diterapkan di Alfamart di wilayah Surakarta

2. Kualitas barang di Alfamart di wilayah Surakarta berbeda dengan minimarket lain.

3. Alfamart di wilayah Surakarta menyajikan barang yang berkualitas.

Dengan adanya upaya peningkatan kualitas barang tersebut, dengan adanya kualitas yang sesuai dengan keinginan konsumen, maka loyalitas Konsumen Alfamart di wilayah Surakarta akan meningkat secara maksimal, sehingga target pernjualan Alfamart di wilayah Surakarta dapat tercapai.

\section{PENUTUP}

\section{Kesimpulan}

1. Hasil Uji Hipotesis

a. Kualitas barang berpengaruh signifikan terhadap kepuasan Konsumen Alfamart di wilayah Surakarta.

b. Strategi harga berpengaruh signifikan terhadap kepuasan Konsumen Alfamart di wilayah Surakarta.

c. Kualitas barang berpengaruh signifikan terhadap loyalitas Konsumen Alfamart di wilayah Surakarta.

d. Strategi harga berpengaruh tidak signifikan terhadap loyalitas Konsumen Alfamart di wilayah Surakarta.

e. Kualitas pelayanan berpengaruh signifikan terhadap loyalitas Konsumen Alfamart di wilayah Surakarta. 
f. Kepuasan berpengaruh signifikan terhadap loyalitas Konsumen Alfamart di wilayah Surakarta.

2. Hasil uji $F$ diketahui besarnya nilai $F$ sebesar 57,579 dan nilai signifikan 0,000 $<0,05$. Sehingga dapat disimpulkan secara bersama-sama variabel kualitas barang, Strategi harga dan kepuasan berpengaruh terhadap loyalitas Konsumen Alfamart di wilayah Surakarta.

3. Hasil tersebut dapat dijelaskan bahwa $R^{2}$ total sebesar 0,918 dapat diartikan loyalitas konsumen Alfamart di wilayah Surakarta dijelaskan oleh variabel kualitas barang, Strategi harga dan kepuasan sebesar $91,8 \%$ dan sisanya $8,2 \%$ dijelaskan variabel lain diluar model penelitian sebagai contoh : lokasi dan sarana prasarana.

4. Hasil analisis jalur menunjukkan bahwa penggunaan intervening kepuasan untuk variabel kualitas barang dan strategi harga adalah tidak efektif. Karena hasil pengaruh langsung lebih besar dibandingkan pengaruh tidak langsung.

\section{Saran dan Rekomendasi}

Berdasarkan hasil penelitian tersebut disarankan agar Alfamart di wilayah Surakarta dalam meningkatkan loyalitas konsumen dapat melakukan hal-hal sebagai berikut:

1. Kualitas barang merupakan variabel paling dominan dalam mempengaruhi loyalitas Konsumen Alfamart di wilayah Surakarta maka dalam meningkatkan loyalitas perlu lebih meningkatkan kualitas barang yaitu dengan cara melihat hasil nilai uji validitas nilai tertinggi dengan teknik one shot methods yaitu menjaga kebersihan barang dan selalu dibersihkan sehingga kualitas barang di Alfamart di wilayah Surakarta punya barang yang spesifik, Alfamart di wilayah Surakarta menyajikan barang-barang yang berkualitas, misalnya barang-barang bermerek yang berbeda dengan minimarket lain.

2. Lingkup penelitian sebaiknya lebih luas lagi tidak hanya Alfamart tetapi lebih luas lagi atau dapat dilakukan dengan berbagai supermarket, agar hasil penelitian bisa dijadikan acuan penelitian yang lebih baik.

\section{DAFTAR PUSTAKA}

Adi, Krismanto, 2007, "Analisis Faktor-faktor yang mempengaruhi loyalitas konsumen", STIE AUB Surakarta.

Anderson, E. and B. Weitz, 2008, "The Use of Pledges to Build and Sustain Commitment in Distribution Channel", Journal of Marketing research 29 (1), p.18-34.

Arikunto, Suharsini, 2011. Prosedur Penelitian Suatu Pendekatan Praktek Edisi ketiga.

Bolton, Ruth N and james H. Drew, 2011, " A Multi Stage Model of Customers Assessment of Service Quality and Value", Journal of Consumer Research, Januari, 1-9.

Bontis, Nick and Lorne D.Booker (2007), " The mediating effect of organizational reputation on customer loyalty and service recommendation in perusahaaning industry", Journal Management Decion, Vol.45, No.9 p.1426-1445.

Brown, Stephen W., 2011, "A Multi Stage Model of Customers Assesment of Service Quality and Value", Journal of Marketing, April, pp. 92-98 
Cronin J.Joseph Jr and Steven A. Taylor (2007), "Measuring Service Quality : A reexamination and extension", Journal of Marketing Vol. 56 (July) p.55-68

Djarwanto dan Subagyo, Pangestu, 2011: Statistik Induktif, Edisi: 4, Yogyakarta: BPFE.

Fornell, Claes; Johnson, Michael D ; Anderson, Eugene W ; Cha, Jaesun; Bryant, Barbara Everitt (2006), "The American Customer Satisfaction Index : Nature, Purpose, and Findings". Journal of Marketing, 60 (10). (7-18).

Ghozali, Imam,2008. Aplikasi Analisis Multivariate Dengan Program SPSS ,2006. Analisis Regresi. Jakarta: Salemba Empat.

Gujarati, Damodar. 2005. Ekonometrika Dasar. Erlangga. Jakarta.

Herbig, Paul, John Milewicz and Jim Golden,(2008). "A Model of Reputation Building and Destruction "Journal of Business Research. Vol.31, June 1994, No. 1 ; p.23-31.

Istijanto,2006, Riset Sumber Daya Manusia, Jakarta:PT. Gramedia Pustaka Utama

Juran, J.M., 2011, Quality Control Handbook, New York: Mc. Graw-Hill.

Kotler, Philip.(2008), Marketting Management, $11^{\text {th }}$ ed. Upper Saddle River, New Jersey : Prentice Hall, Inc.

Liu, Tsung-Chi and Li Wei Wu (2007), "Customer retention and cross-buying in the perusahaaning industry : An Integration of service attributes, satisfaction and trust" Journal of Financial Service Marketing, Vol.12 No.2 p.132-145.

Marius, 2009, Consumer Behavion and Price, $5^{\text {th }}$ edition, McGraw Hill, New York, NY

Mandela, (2007), "Study Mengenai Loyalitas Konsumen Pada Rumah Makan Start Stick (Studi khusus di wilayah Surakarta)", Jurnal Sains Pemasaran Indonesia, Vol III, No.3, Desember 2007. (289-308)

Oliver, Richard L. (2007), "Satisfaction : A Behavioral Perspective on the Customer", McGraw-Hill, New York, NY

Parasuraman, A.,A.Zeithmal, V.,\& L.Berry, L.2005" A conceptual Model of Service Quality and Its Implications for Future Research", Journal of Marketing, Vol.49 (fall).

Peraturan Pemerintah Republik Indonesia No.25 tahun 1980 tentang perubahan atas Peraturan Pemerintah No. 26 tahun 1965 tentang Perusahaan.

Prichard, mark P, 2010, "Analyzing the Commitment-Loyalty Link in Service Contexts", Journal of the Academy of Marketing Science 27 (3), p.333-348

Riduwan, 2005, Skala pengukuran Variabel-Variabel Penelitian, Cetakan Ketiga, Alfabeta, Bandung. 
Selnes, Fred (2008), "An Examination of the effect of Product Performance on Brand Reputation, Satisfaction and Loyalty", European Journal of Marketing, 27 (9). (1935).

Setyo, Budiarto, 2011, "Pengaruh Kualitas Pelayanan terhadap Loyalitas Konsumen dan Citra perusahaan sebagai Variabel Intervening pada Apotek K-24 Jogjakarta" Pustaka Pelajar, Yogyakarta.

Solomon, Michael (2006), Consumer Behavion, $3^{\text {th }}$ edition, McGraw Hill.

Sugiyono, 2011. Metodologi Penelitian Bisnis, Cetakan Keenam, CV. Alpabeta, Bandung.

Tjiptono, Fandi, 2007, Prinsip-prinsip Total Quality Service (TQS) , Andi Offset, Yogyakarta.

Zeithaml, V.(2008), Consumer Perceptions of Price, "Quality, and Value : Means End Model and Synthesis of Evidence", Journal of Marketing, Vol 52, July, p.2-22

Zeithaml, Valerie; Berry, Leonard L and Parasuraman, A. (2008), "Sevqual: Multiple Item Scale for Measuring Consumer Perceptions of Service Quality", Journal of Retailing, Vol 64 No. 1 Spring. 